\title{
Práticas e Contradições: um estudo de caso sobre camponeses assentados no Médio São Francisco
}

\author{
Lidia Maria Pires Soares Cardel ${ }^{1}$ e Rejane Alves de Oliveira $^{2}$
}

\begin{abstract}
Resumo: Este trabalho tem a proposta de apresentar o modo de vida de um grupo social camponês e sua história de constantes intervenções governamentais. Esta comunidade, denominada Canudos, é um assentamento localizado no interior do estado da Bahia, na região do Médio São Francisco. Os sujeitos sociais abordados no artigo oscilam entre atividades pluriativas, das quais as principais são o trabalho com a terra e com a pesca artesanal, e apresentam sociabilidades, relações familísticas e identitárias singulares. Constatamos que esta distintividade, baseada principalmente na precedência de alguns grupos familiares, gera conflitos internos que se potencializam e dificultam a implementação de projetos intervencionistas por parte do Estado. $\mathrm{O}$ artigo busca analisar esta prática e as contradições deste processo social. Os dados analisados foram coletados por meio de uma fusão metodológica entre a técnica de estudo de caso aprofundado e a análise de diagnóstico dos sistemas agrários.
\end{abstract}

Palavras-chaves: Campesinato, assentamento, identidade, agricultura familiar, mediadores.

\begin{abstract}
This work aims to present the way of life of a peasant social group and its history of constant government interventions. This community, called Canudos, is located in Bahia State, in the Médio São Francisco area. The social actors to which we refer move within pluriactive activities (farm work and small-scale fishing are the most important), and present unique sociabilities, familistic and identitary relations. We have verified that this distinctiveness, which is based mainly on the precedence of the several family groups, generate internal conflicts that become powerful and make it difficult for the government to implement intervention projects. This article intends to analyze this practice and contradictions of this social process. Data were collected from a methodological fusion between the technique of in-depth case study and diagnosis analysis of the land systems.
\end{abstract}

Key-words: Peasantry, settlement, identity, family farming, mediators.

Classificação JEL: 18R.

1 Prof ${ }^{a}$. Dra . Adjunto do Departamento de Sociologia da Universidade Federal da Bahia, membro da pós-graduação em Ciências Sociais e coordenadora do Núcleo de Estudos Ambientais e Rurais Nuclear/UFBA. E-mail: lcardel@uol.com.br

2 Doutoranda pelo programa de pós-graduação em Ciências Sociais da Universidade Federal da Bahia, Estudante filiada à Associação Brasileira de Antropologia (ABA) e associada ao Núcleo de Estudos Ambientais e Rurais - Nuclear/UFBA. E-mail: realves13@gmail.com 


\section{Introdução}

Por campesinato, geralmente, entende-se o modo de vida de um grupo social de base familística, que se utiliza de mão de obra familiar para garantir a reprodução da unidade doméstica, comumente ligada a atividades agrícolas. Da mesma forma, o termo camponês foi primeiramente relacionado ao labor com a terra, e só posteriormente ganhou amplitude maior - ribeirinhos, beradero ${ }^{3}$, agricultores familiares. É vinculada a uma definição mais ampla e heterogênea que nos propomos a estudar o modo de vida de um grupo social camponês que apresenta várias particularidades, e não apenas o trabalho com a terra. Os sujeitos sociais a que nos referimos realizam várias atividades, mas nenhuma delas é exclusiva. Os camponeses, protagonistas desta pesquisa, oscilam entre atividades com a terra seca (caatinga), a terra molhada (lameiro), e a cadência das águas do "Velho Chico". Do mesmo modo que não há uma atividade exclusiva, não há uma identidade única no grupo. Os sujeitos sociais possuem pluri-identidades - tra-

3 Conforme Estrela (2004), ser beradero é ser um indivíduo que possui um saber fazer específico; é tirar do rio diretamente ou indiretamente o seu sustento; é ser representado pelo trabalho por meio da rede ou da canoa; ser beradero é trabalhar na chuva e na vazante; é saber viver entre a caatinga e o lameiro; é praticar a agricultura de sequeiro e de ilha; é viver entre o ir e vir entre os espaços de vida e de trabalho. balhador rural, atravessador, lavrador, pescador artesanal, pescador/lavrador e vice-versa. Neste trabalho, procura-se caracterizar o modo de vida de uma comunidade de pescadores artesanais e agricultores familiares, beraderos do Médio São Francisco, e sua história de constantes intervenções governamentais.

O assentamento de Canudos ${ }^{4}$ aparenta ser uma comunidade camponesa típica do semiárido nordestino. No entanto, as ações oriundas de políticas públicas implementadas em uma área de assentamento e a instalação de famílias com históricos de sociabilidades distintas alteraram sua constituição. A produção científica sobre campesinato nos mostra que as estruturas de sociabilidades, alianças, parentesco, compadrio e amizades são basilares para a reprodução do modo de vida camponês. Entretanto, no assentamento de Canudos, este arcabouço não se estrutura. Há uma baixa organização estrutural entre os seus grupos domésticos. Durante o trabalho de campo, constatamos que vários projetos institucionais foram implantados nessa localidade, mas as ações e intervenções governamentais não foram incorporadas pelo grupo como elementos agregadores de valores materiais e simbólicos. $\mathrm{O}$ que se pôde perceber foi que os moradores de

4 O assentamento de Canudos localiza-se a $24 \mathrm{~km}$ da cidade de Barra (sede do município). O município de Barra está situado no noroeste do estado da Bahia, na região do Médio São Francisco, a 700 km de Salvador. 
Canudos, mesmo compartilhando determinadas sociabilidades, não tornaram possível o desenvolvimento de ações conjuntas frente aos projetos promovidos por políticas públicas governamentais e institucionais.

\section{Fundamentação teórico-metodológica}

Em função da relação conflitual presente entre os assentados de Canudos oriundos de localidades distintas, procurou-se averiguar a motivação dos conflitos internos e problematizar a crença dos mediadores (CPT, Incra, Sindicato Rural, entre outros) de que os grupos rurais centenários que vivem em condições difíceis esperam ansiosamente por intervenções institucionais. Em muitos casos, não existe uma preocupação prévia com a incorporação dessas medidas, pois os mediadores acreditam que não haverá resistência frente a projetos que tragam melhorias.

Assim sendo, busca-se desvendar as características antropossociológicas que determinam a continuidade e a descontinuidade das formas de organização familiar dentro deste assentamento do Incra, descrevendo quais são os elementos constitutivos da produção camponesa nos territórios de terra e água, além das peculiaridades deste grupo social. Por conseguinte, abordamos o modo como este grupo específico de lavradores e pescadores artesanais enfrenta o desafio de resistir aos mecanismos de políticas públicas que destoam de sua realidade empírica (imposição de projetos coletivos e subordinação ao direito positivo $^{5}$ ). E, por meio deste enfoque, buscare-

\footnotetext{
5 Segundo a literatura antropológica e sociológica sobre a organização social das comunidades rurais brasileiras (HEREDIA, 1979; GARCIA JR, 1983; WOORTMANN, 1990, entre outros) o direito consuetudinário, ou seja, o direito costumeiro estabelece de forma primordial as relações sociais intrafamiliares das comunidades camponesas. Com relação a Canudos, a comunidade pesquisada, observa-se que a chegada do Estado significou a chegada do direito positivo e o embate deste com o direito consuetudinário. De uma hora para outra, o direito costumeiro não escrito, fundado no uso, nos costumes, na prática, no respeito e na teia de reciprocidade social dessas populações centenárias passou a ser tencionado e pressionado, para dar lugar ao estranho direito da lei escrita.
}

mos mostrar, por outro lado, que existe por parte destes sujeitos a incorporação racional de certas ações de políticas públicas modernas e primordiais (como o programa Bolsa Família e as aposentadorias rurais e especiais), que garantem a sobrevivência dos grupos domésticos, alterando a sua própria reprodução social e a configuração da comunidade de Canudos.

O trabalho de campo para a coleta dos dados apresentados ocorreu entre 2007 e 2010. Nos contatos iniciais foram levantadas questões relacionadas à caracterização do modo de vida dos assentados (agrovila, território de plantio, pesca artesanal e produção) e dos projetos implantados na comunidade (casa de farinha coletiva, aprisco e projeto de irrigação) por meio das técnicas de depoimentos e leitura de paisagem. Posteriormente, foram usadas as técnicas de registro fotográfico e iconográfico dos espaços, a observação das atividades cotidianas com o uso do diário de campo, entrevistas temáticas e questionário com perguntas fechadas e abertas ${ }^{6}$. Também foram usados como fonte de pesquisa documentos oficiais, como o Plano de Desenvolvimento Sustentável do Projeto de Assentamento, a Relação de Beneficiários ambos fornecidos pelo Incra -, dados do IBGE e da SEI (Superintendência de Estudos Econômicos e Sociais da Bahia), assim como documentos da Secretaria Municipal de Saúde. Por essa razão, há uma flexibilidade metodológica aparente, que é a combinação de entrevistas temáticas, recortes de

\footnotetext{
6 Nas entrevistas, foram privilegiados os diálogos com pessoas de mais idade (entre 40 a 75 anos), que, além de tópicos preestabelecidos, debruçaram-se sobre a história da comunidade, o surgimento do assentamento, a relação entre as famílias assentadas, a herança do patrimônio e sobre os projetos implantados na comunidade. Tivemos acesso à ficha cadastral de todas as unidades domésticas, com dados sobre origem, número de filhos, condições de moradia, uso de fontes de energia, condições de higiene, doenças preponderantes e usos de plantas medicinais. Foram aplicados, como técnica auxiliar, surveys com famílias assentadas e não assentadas. As questões deste procedimento versavam sobre a situação patrimonial, a renda familiar, a divisão de trabalho, as relações de vizinhança, as propriedade de bens, as opiniões sobre a implantação de projetos e a relação mantida com a associação de trabalhadores rurais e de pesca.
} 
jornais, depoimentos e descrição de atividades pautadas em anotações de campo.

Estas técnicas diversas foram integradas ao recurso da metodologia de análise de diagnóstico de sistemas agrários, com a finalidade de compreender os distintos sistemas de produção, as estratégias de geração de renda e as formas de trabalho direto e acessório das unidades familiares. Um dos principais approaches dessa metodologia é a separação dos sistemas produtivos dos grupos domésticos em sistemas distintos: as áreas específicas de plantio (os roçados), as diversas formas de extrativismo pelo território da comunidade (de terra e de água) e a utilização dos quintais domésticos de acordo com a divisão social do trabalho pautado na relação de gênero e geração. Esta metodologia garante uma análise comparativa sobre os diferentes modos de uso dos espaços, no sentido confirmado por Dufumier (2007), e demonstrou, por meio das técnicas utilizadas, que as políticas públicas voltadas para a criação e a estruturação dos Assentamentos Rurais não abarca a diversidade empírica do homem rural brasileiro.

Segundo alguns estudiosos (CARVALHO, 1999), a criação de um projeto de assentamento é o produto formal de um ato administrativo, expresso no decreto de desapropriação de uma área rural e, por outro lado, é o resultado de lutas sociais para a redistribuição da posse da terra. Portanto, no momento da criação de um assentamento rural, se encerraria um processo político-social em que o monopólio da terra e o conflito social pela posse da terra estariam superados, e imediatamente se iniciaria outro, também de grande complexidade. Este segundo momento é o período do parcelamento da terra; da construção de novas estradas; da seleção dos locais para a edificação das casas; da extensão da rede de eletrificação rural; da destinação de áreas para uso social comum; da liberação de créditos e da construção de cercas e apriscos, currais ou escolas, igrejas e campos para jogos; da compra de animais e de implementos agrícolas; do início dos plantios e das criações. Entretanto, conforme a apreciação de Carvalho, não é apenas a infraestrutura produtiva e de uso social ou o processo de produção que se inicia. Nesta ocasião, desencadeia-se, também, o desenvolvimento de novos ajustes e adaptações de experiências política, social e ideológica, correspondentes à nova organização social que ali se plasma empiricamente. Ocorre a criação de associações, de cooperativas ou de grupos de trabalho, como também se inicia a formação de grupos de lazer e o estabelecimento de novas relações de vizinhança, de afinidades religiosas, políticas e ideológicas, que poderão ser ora objetos de consenso e ora de dissenso.

De acordo com Martins (2003), em um assentamento rural, as relações de vizinhança e amizade, a construção da memória coletiva, a formação de grupos de trabalho ou o sentimento de comunidade não se desenvolvem tão facilmente quanto Carvalho supõe, principalmente se o assentamento não é fruto de lutas gestadas por movimentos sociais, como é o caso de Canudos. Ou seja, não havendo anteriormente uma identidade de mobilização ou de acampamento, a identidade grupal não se gestará facilmente. Neste sentido, a concepção de um assentamento não segue a dinâmica e as possibilidades do mundo camponês, e os desencontros de orientação dos agentes de mediação estimulam conflitos internos e potencializam o débito de sociabilidade, gerando conflitos reais e ideológicos. Estes conflitos demonstram os processos de negociação dos trabalhadores rurais e camponeses frente a uma situação social completamente diferente daquilo que eles conhecem e do que eles desejam, já que o assentado passa a conviver não só com os benefícios da modernização, mas com as dilacerações que a modernização impõe a todos aqueles que procedem da sociedade concebida como tradicional. Ser um assentado é viver as incertezas da inserção social, baseada em ações de resistência e de adaptação ao mesmo tempo. Por outro lado, como argumenta Martins, o sujeito nasce também das mediações conflitantes desta trama introduzida pela ação e pelas concepções de outros protagonistas, como o Estado e as organizações mediadoras representativas. Apesar destas contradições, e por mais 
que nos pareça incompreensível à primeira vista, é por meio deste referido sujeito conflitual que a agricultura familiar brasileira persiste, insiste e se reconfigura na atualidade.

Esta pesquisa busca pensar esta prática e as contradições desse processo. Trata-se aqui de superar a concepção de que o mundo rural tem uma ordem social harmônica. $\mathrm{Ou}$, como afirma Martins, "começar a pensar o presente como um conjunto de contradições que, ao se resolverem, engendram novas contradições, novos desafios, renovações da prática" (MARTINS, 2003, p. 19). Contradições que foram renovadas não apenas com a criação de um espaço físico artificial e civilizador, mas foram positivadas com o assentamento de famílias centenárias e grupos domésticos de outras regiões, inclusive da área de Sobradinho ${ }^{7}$. A fixação de grupos domésticos, com sociabilidades e relações familísticas distintas, criou categorias e distintividades, baseadas na precedência de um grupo familiar sobre outro.

A Sociologia Rural explica este mundo como uma realidade à parte, como um universo sui generis que perpassa temas, como identidade camponesa, campesinidade, assentamento, deslocamento, conflito, mediadores e pluriatividade. E será por meio da apropriação do pensamento de autores como Queiroz (1973), Heredia (1979), Velho (1982), Woortmann (1997), Godói (1999), Elias (2000), Martins (2003) e Sigaud (2005) que a discussão sobre a prática e as contradições deste universo será guiada. Foi a partir destas leituras etnográficas e sociográficas e da relação com o campo empírico que este trabalho foi construído. Desta forma, por meio de um processo reflexivo entre a empiria e a teoria, autores específicos e conceitos-chave foram incorporados à medida que o trabalho de campo foi sendo realizado e contribuíram para a análise do objeto de estudo.

\footnotetext{
7 A construção da usina ocorreu de 1972 a 1978; o reservatório atingiu $300 \mathrm{~km}$ de comprimento e teve 5.400 $\mathrm{km}$ desocupados. Atingiu os municípios baianos de Pilão Arcado, Remanso, Casa Nova, Xique-Xique, Sento Sé e Juazeiro. Foram deslocadas aproximadamente $72 \mathrm{mil}$ pessoas. Sobre este assunto ver: Daou (1988), MartinsCosta (1989) e Estrela (2004).
}

\section{Apresentação do campo estudado}

Canudos é uma agrovila composta por 115 famílias, tendo, em 2010, 458 habitantes; destes moradores, 235 são do gênero masculino e 223, do feminino. Das 115 famílias da comunidade, apenas 104 são assentadas e 11 aguardam vaga para serem assentadas. Em Canudos foram assentadas tanto pessoas que haviam nascido na fazenda Barro Vermelho/Canudos há muitas décadas quanto famílias da região de Remanso (BA), Pilão Arcado (BA), Xique-Xique (BA) e Brejos (distrito rural da cidade baiana de Barra). Estas famílias foram se deslocando pela região antes e depois da década de 1970 e muitas delas podem ser consideradas como atingidas e deslocadas indiretamente pelo reservatório de Sobradinho, pois são famílias que deixaram a região de Remanso ou Pilão Arcado por ouvirem falar da construção da usina e por acreditarem que, como não detinham o título de propriedade da terra, seriam retirados sem nenhuma forma de indenização.

Para ser assentado em Canudos, é preciso que outra família desista do assentamento, ou que o assentado venha a falecer, sem deixar um cônjuge legalmente cadastrado no programa. Quando um grupo familiar desiste do assentamento, ele não pode vender o lote, nem a casa que lhe foi repassada. Entretanto, esta norma não é seguida, e muitos assentados costumam vender seus lotes por preços irrisórios para famílias que buscam ser assentadas ou para famílias assentadas que desejam aumentar seus espaços de produção. Se o assentado for um viúvo ou divorciado e vier a falecer, os terrenos onde trabalhava terão suas divisas respeitadas, até que um filho que demonstre interesse tenha seu nome aprovado em assembleia e a associação da comunidade envie nome e documentos ao Incra. Não havendo cônjuge ou filhos, o Incra é avisado da vaga, mas a associação geralmente indica o nome de alguém que vive na localidade e que já adquiriu as benfeitorias antecipadamente.

Na comunidade de Canudos existiram famílias originárias que optaram por não serem assentadas. Estas famílias não moram mais em 
Canudos, pois explicitaram descontentamento com a nova realidade e se recusaram a serem assentadas e, posteriormente, deixaram a comunidade. Conflitos como este, em que famílias inteiras abandonam a área de um futuro assentamento, foram retratados por Loera (2006), que constatou que a proposta de trabalho coletivo e de plantio em áreas comunais teria feito famílias cadastradas pelo programa, no interior de São Paulo, abandonarem a área onde estavam vivendo provisoriamente para voltarem para uma área de acampamento e buscarem nova oportunidade de serem contempladas em outra localidade. Silva (2004) também aponta para esta questão e afirma que a coletivização dos lotes e a pressão para a formação de cooperativas, imposta em vários assentamentos pelos mediadores, é uma experiência fracassada. Em muitos casos, há uma recusa dos assentados ou das famílias cadastradas frente às propostas de assentamento que quebrem e imponham bruscamente um novo modo de vida, pautado na modernização das suas relações socioeconômicas, por meio da criação de relações mais "civilizadas e desenvolvidas".

As 115 famílias residentes no assentamento têm algum parentesco com uma ou mais famílias da comunidade, pois, afinal, antes de ser um assentamento, Canudos era uma comunidade centenária. $\mathrm{O}$ parentesco entre assentados e famílias ainda não assentadas é uma das questões apontadas por vários pesquisadores (SIGAUD, 2005; LOERA, 2006), pois as redes de informação e benefícios distribuídos pelo Incra são inicialmente formadas entre parentes e amigos. Segundo Rebouças (1997), a importância dos grupos domésticos nos assentamentos pode ser observada na construção de puxados e casas fora do padrão, construídas por parentes e agregados que se unem às famílias contempladas, na esperança de um dia também serem contempladas. Os puxados e as casas fora do padrão também são comuns na comunidade de Canudos. Das 157 construções existentes, 133 são habitadas e as demais são vendas, centro comunitário, escola, igreja, casa de farinha, casas abandonadas fora do padrão ou puxados. Das construções habitadas,
90 são de tijolo ou bloco, 42 são de taipa ou adobe e uma, de madeira. As casas construídas com adobe ou taipa de mão são habitadas por famílias que ainda não foram contempladas por residências construídas pelo Incra e pela $\mathrm{CAR}^{8}$, ou são de famílias que esperam ser assentadas.

Como em vários outros projetos de assentamento (REBOUÇAS, 1997; ESTRELA, 2004), o projeto para a implantação de Canudos obedeceu à concepção de um espaço organizado em conformidade com um "projeto civilizatório" idealizado pelo Incra. A organização física do assentamento de Canudos privilegia a visão da urbanidade. As residências da agrovila se alinham dentro de uma uniformidade relativa e se distribuem por quatro ruas: Rua do Sossego, Rua das Flores, Rua Principal e Rua Santo Antônio. Neste projeto civilizador, há não só uma separação entre os espaços de morada e o ambiente de trabalho, que influencia o tempo de trabalho nesse espaço de plantio, colheita ou pesca; mas existe, acima de tudo, um traçado urbano (ruas, medidas de quintais) que interfere na sociabilidade dos envolvidos. A divisão entre espaço de moradia e de trabalho é grave em Canudos, pois, apesar de o assentamento existir desde 1997, até o momento, o Incra não fez a demarcação dos lotes. Em função desse problema, algumas pessoas ainda plantam na beira do rio e nas proximidades da agrovila. Mesmo assim, aqueles que plantam em lotes mais distantes, com pelo menos uma hora de caminhada, reclamam do tempo gasto no trajeto e dos frequentes roubos de ferramentas e produtos.

Woortmann (1991) chama a atenção para o aspecto negativo desta fragmentação territorial, enfocando os problemas causados por esta separação física entre o espaço da morada e o espaço do trabalho. Para a autora, o cercamento do espaço casa/quintal é uma mudança altamente prejudicial, pois, ao lado da sua redução real, não só se reduz a atividade aí realizada, mas alteram-se as relações de vizinhança, o que, por sua vez, aumenta as tensões entre as famílias vizi-

\footnotetext{
8 Companhia de Desenvolvimento e Ação Regional do Estado da Bahia.
} 
nhas, criando-se verdadeiras guerras de cercas e restringindo, sobremaneira, a criação de animais que colaboram para a economia de consumo dos grupos domésticos. Em Canudos, os vizinhos discutem por causa do barulho de aparelhos eletrônicos, por roubos de pequenos animais nos quintais, falta de espaço para criarem porcos ou galinhas e animais que invadem as roças de caatinga, já que estas raramente são cercadas.

A opção pela agrovila trouxe a possibilidade de espaços comerciais, educacionais, edificações comunitárias, instalações de rede de água tratada e elétrica, mas trouxe também contendas diretamente relacionas ao adensamento dessas famílias. O descontentamento subliminar dos assentados de Canudos (não houve recusa ao projeto por parte da maioria das pessoas), com o espaço e com o que ele gerou, lentamente parece ter levado os próprios moradores a destruírem as áreas e os equipamentos comuns, como casa de farinha, canos de irrigação, aprisco, bombas d'água e implementos agrícolas. Todas estas benfeitorias construídas pelos órgãos governamentais e por meio dos projetos elaborados pelos mediadores (CPT, ONGs) foram destruídas pelos assentados, que não conseguiram se apropriar conjuntamente desta infraestrutura por meio de uma coletivização e/ou de uma divisão equitativa de trabalho.

Experiência similar é retratada por Estrela (2006), que afirma que, em relação aos equipamentos comunitários, o Projeto de Serra do Ramalho implantou duas novidades: a construção de lavanderias e a implantação de refeitórios públicos nas agrovilas. Entretanto, os equipamentos não conseguiram ser apropriados funcionalmente e foram destruídos pelos próprios moradores. Conforme relata a autora, das edificações instaladas, restam apenas as ruínas. Observa-se, desta forma, que a padronização das comunidades camponesas em agrovilas mostrou ser uma "faca de dois gumes".

Seguindo esta mesma linha, para Rebouças (1997), a ideia de oposição entre rural-urbano influenciou a forma com que a Cesp ${ }^{9}$ direcionou

9 Companhia Energética de São Paulo. a criação dos assentamentos sob sua responsabilidade. A autora acredita que a ambição do projeto da Cesp, em sentido amplo, não é apenas a fixação do homem no campo, mas também inserir as comunidades ribeirinhas no desenvolvimento do progresso. O projeto civilizador apresentado por esta Companhia seria levar aos ribeirinhos os benefícios de serviços e infraestrutura dos quais eram desprovidos: água, energia elétrica e serviços sociais em núcleos habitacionais.

Canudos, do mesmo modo, teve acesso ao sistema de água encanada e tratada implantada pela prefeitura de Barra ${ }^{10}$; no entanto, das 115 famílias que viviam em Canudos em 2007, apenas 45 dispunham de água encanada e as outras 70 famílias utilizavam a água do rio para beber e cozinhar alimentos. A luz elétrica também chegou à comunidade. Entretanto, dentre as 115 famílias, apenas 76 tinham a instalação, enquanto 39 ficaram fora das áreas beneficiadas. Porém, muitas famílias que tinham luz elétrica estavam com o fornecimento cortado por falta de pagamento ou enfrentavam dificuldades para manter o pagamento em dia ${ }^{11}$. A falta de água também determina o traba-

10 A água encanada utilizada em Canudos é bombeada do rio São Francisco, coletada em uma comunidade próxima, denominada Wanderley. A água é tratada manualmente em um reservatório e depois distribuída para Canudos e Barro Vermelho pelo sistema de distribuição de água, gerenciado pela Prefeitura Municipal de Barra.

11 Em oficina realizada em 07/12/2007, coordenada pela professora doutora Lídia Cardel (UFBA), em que a temática era o direito à tarifa social de energia elétrica (Lei n. 12.212) e o direito à água era visto como um bem de domínio público (Artigo 1ํㅡㄹ inciso I da Lei n. 9.433/97), 98 famílias participaram. A tarifa social de energia discutida na oficina estabelece que famílias com o perfil do programa bolsa família, cuja renda per capita é de R\$140,00, e que tenham consumo entre 80 e $220 \mathrm{kwh}$, têm direito a uma tarifa de energia diferenciada. Até $30 \mathrm{kw} / \mathrm{h}$, o desconto é de $65 \%$; entre 31 e $100 \mathrm{kw} / \mathrm{h}$, o desconto é de $40 \%$ e, entre 101 e $220 \mathrm{kw} / \mathrm{h}$, o desconto é de $10 \%$. A lei que define a água como um bem público concretiza o disposto no Artigo 225 da Constituição Federal de 1988. Nesta oficina, foram verificados empiricamente quatro problemas. Primeiro: ao analisar os valores tarifários de luz e água cobrados pela Coelba (Companhia de Eletricidade do Estado da Bahia) e pelo município de Barra, constata-se que todos tinham problemas de pagamento com uma ou com outra empresa; segundo: verifica-se que, apesar de várias famílias fazerem parte dos programas assistenciais do governo federal, os valores cobrados em suas contas de luz não correspondiam aos valores (legalmente) estabelecidos para 
lho excessivo de mulheres e crianças na beira do rio São Francisco. É comum encontrar mulheres e meninas lavando roupas e utensílios domésticos nos horários mais quentes do dia.

Esta é a realidade observada na comunidade de Canudos no período do trabalho de campo deste artigo. De um lado, lugares de trabalho e de vida parecem, momentaneamente, estar desarticulados em função dos descompassos entre os processos impostos pelas políticas públicas voltadas para áreas de assentamento; por outro, parece haver um sentido por trás dos conflitos e dos processos vividos na história recente deste grupo social, que remete à concepção de que os processos de sociabilidades e de historicidades de grupos sociais impactados são sempre complexos e ambíguos. Nesta conjuntura, esta realidade altamente fluida não é uma característica apenas desta comunidade camponesa, na medida em que ela está inserida numa realidade mais ampla, que a transversaliza constantemente.

\section{Análise dos dados}

Assim, procura-se representar o modo de vida desta população, compreendendo o "conflito" como algo processual, e buscando mostrar que o seu modus vivendi camponês, mesmo inserido em uma área de assentamento com disputas internas entre os grupos sociais, ainda é latente e tem uma forma particular de organizar e classificar o mundo desta comunidade. Ainda que os grupos domésticos de Canudos sejam diferenciados, existem determinados aspectos que os definem e os unificam, como, por exemplo, a utilização da mão de obra familiar, a produção voltada para o sustento da família e a prática da policultura. Por essa razão, parte-se do princípio de que os mora-

pessoas cadastradas nesses programas; terceiro: os poucos eletrodomésticos (televisão, aparelho de som, geladeira e freezer) que os moradores têm são antigos, o que eleva o consumo de energia elétrica; quarto: o município cobra o dobro do valor tarifário da água para casas em que o mínimo consumido denominado de cota social (10.000 litros) é excedido, ignorando o fato de que a região do semiárido deveria ter um consumo mínimo diferenciado das residências urbanas. dores desta comunidade se aproximam da concepção construída por Woortmann (1990), de que estes camponeses não veem a terra apenas como um objeto mercadológico, mas como um patrimônio familiar em que terra, trabalho e família são elementos centrais. Esta representação social é inerente à cosmologia e à cosmografia da comunidade de Canudos, em que o patrimônio do grupo doméstico é simultaneamente um lugar de moradia e de produção e a família é a unidade de produção e de consumo.

Destarte, o cotidiano dos moradores de Canudos, cadenciado entre água e terra, entre o trabalho no lameiro, na vazante e na caatinga, está vinculado à prática de três atividades principais: extrativismo vegetal, plantio e pesca. No assentamento de Canudos, a atividade de extração é realizada fundamentalmente na caatinga e no entorno da comunidade; o plantio de alimentos se dá em quintais, roças da caatinga, roças de beira de rio e em roças de ilha; e o pescado é obtido por meio da pesca artesanal no "Velho Chico". Essas atividades são realizadas em territórios distintos, em momentos variados e por agentes diferenciados, uma vez que as divisões dos grupos, assim como as divisões das atividades, são caracterizadas por uma divisão de gênero e geração.

Nesta complexa teia de relações sociais, em que a vivência se entrelaça entre as ações e as relações reificadas em territórios distintos, a categorização de Canudos por meio de um conceito único não parece algo simples de ser estabelecido. $\mathrm{Na}$ discussão a seguir, procura-se estabelecer linhas teóricas e empíricas que possam desvelar o imaginário e o cotidiano desta comunidade.

Apesar de uma extensa produção científica sobre comunidades camponesas mostrar que as estruturas de sociabilidades, alinhavadas pelas relações de parentesco (reais ou imaginárias), compadrio, alianças e amizades são basilares para a reprodução do modo de vida camponês, mesmo que se tenha conhecimento de que o assentamento de Canudos apresenta fraturas na sua organização social, e ainda que se tenha ciência de que a condição vivida no assentamento de Canudos decorre de uma rede de processos 
complexos e conflituosos, sabe-se que esse assentamento se constitui, de fato, num lugar experienciado de reprodução do modus vivendi camponês ou de campesinidade. Tal qual Woortmann (1990) em “Com parente não se neguceia: O campesinato como ordem moral", optou-se por pensar Canudos por meio da ideia de campesinidade no lugar da de camponês.

Como este autor argumenta, não existe um camponês puro, e o conceito de campesinidade, com todas as suas variações, explicaria os diversos caminhos que um grupo como o de Canudos pode apresentar - estabelecidos ou chegantes, assentados ou não assentados, pescadores ou lavradores. Assim, o que existe é uma campesinidade comum a todos, mesmo havendo diferenças empíricas essenciais entre o campesinato histórico brasileiro. Como frisou Weber (1980), "de todas as comunidades, a constituição social dos distritos rurais são as mais individuais, e as que relação mais íntima mantêm com determinados fatos históricos" (p. 89).

O campesinato, para muitos teóricos (QUEIROZ, 1973; HEREDIA, 1979; GARCIA JR., 1983; MOURA, 1988; WOORTMANN, 1997; CANDIDO, 2001), possui uma organização baseada na terra, no trabalho e na família, e na concepção do uso destes bens materiais e imateriais como um valor. Para esses teóricos, a especificidade deste grupo social não implica a negação de uma forma de subordinação à qual pode estar submetido, nem sugere a negação de uma multiplicidade de estratégias por ele adotadas diante de diferentes situações, de diferentes tempos ou lugares. Os grupos sociais podem apresentar maior ou menor grau de campesinidade segundo a trajetória histórica e social de cada um e a sua forma de integração à sociedade moderna. São essas multiplicidades de estratégias que podem levar a uma maior ou menor reprodução de campesinidade. De acordo com Woortmann (1990), a campesinidade está fundamentada por uma ética camponesa, ${ }^{12}$ o que expressa a existência de uma

12 A ética camponesa apresenta terra, trabalho e família como valores morais e categorias intimamente relacionadas entre si e tem como princípios norteadores a honra, a hierarquia e "ordem moral, isto é, de uma forma de perceber as relações dos homens entre si e com as coisas". A campesinidade é uma categoria encontrada em momentos e lugares diferentes, que expressa a importância de valor da ética camponesa para pessoas ou para grupos sociais. Trata-se, portanto, de uma característica presente, em maior ou menor grau, que é compartilhada.

Velho (1982) trata claramente de campesinidade ao expor a necessidade de tentar fugir da ideia de contradição, quando se depara com uma multiplicidade de situações empíricas não teorizadas, entre o ideário de um camponês sem-terra e um proletário com consciência camponesa. Foi teorizando o empírico que Velho criou a hipótese de um continuum camponês-proletário. $\mathrm{Na}$ área por ele estudada (sul do Pará), existiam dois tipos sociais: um que vivia isolado com sua família na mata e outro que vivia em pequenas comunidades. Entre eles, foi observado que poucos se dedicavam exclusivamente à atividade agrícola, pois também trabalhavam nos castanhais durante a safra. Eles tinham, portanto, dois papéis - agricultores e apanhadores. A análise do empírico possibilitou ao teórico compreender e definir tipos ideais. Tinha-se, segundo o autor, um camponês agricultor autônomo (produção quase exclusivamente de subsistência, integração mínima no sistema nacional) atingindo um grau máximo de autonomia; porém, se olhássemos para os trabalhadores dos engenhos na Zona da Mata Pernambucana, tinha-se o máximo de dependência ou de proletarização (terra escassa, mão de obra abundante e alta integração com o sistema nacional). Os casos intermediários, existentes abundantemente no Nordeste, de parceiros, meeiros, arrendadores e outros, justificam a hipótese de um continuum camponês-operário estabelecido por Velho, ou, como prefere Woortmann, justificam o conceito abstrato de campesinidade.

a reciprocidade. Para o autor, ela forma uma ordem moral de forte inspiração religiosa, constituindo inclusive uma ideologia tradicional oposta à ordem social da modernidade. Tanto que, no Brasil, a ética do catolicismo rústico se confunde com a ética camponesa. Sobre esse assunto, ver Woortmann,1990 e Queiroz, 1976. 
Esse continuum, posteriormente, vai ser definido (SCHNEIDER, 2003; DUFUMIER, 2007) como uma estratégia de sobrevivência, denominada pluriatividade.

São situações sociais em que os indivíduos que compõem uma família com domicílio rural passam a se dedicar ao exercício de um conjunto variado de atividades econômicas e produtivas, não necessariamente ligadas à agricultura ou ao cultivo da terra, e cada vez menos executadas dentro da unidade de produção (SCHNEIDER, 2003, p. 100-101).

Segundo Schneider (2003), a dinâmica da própria agricultura no espaço rural vem sendo condicionada e determinada por outras atividades. Dessa mudança estrutural temos o exemplo da expansão das unidades familiares pluriativas como uma estratégia de reprodução social e econômica das famílias rurais. A noção de pluriatividade dá, segundo o autor, a possibilidade de aprender melhor, não só as formas de trabalho, mas também a renda das unidades familiares. A importância desta estratégia tem graus variados de acordo com as regiões. No entanto, essa estratégia não significa um rompimento com as particularidades do campesinato brasileiro, afinal, atividades não agrícolas sempre foram realizadas no dia a dia desses grupos sociais. Como exemplo, há unidades familiares em Canudos em que a mulher é faxineira na escola municipal da comunidade e, ao mesmo tempo, desempenha atividades no quintal e na roça de ilha e caatinga do seu grupo familiar. A estratégia pluriativa mantém a unidade doméstica enquanto um grupo produtor e consumidor e não nega a reprodução social tradicionalmente desenvolvida por meio de uma ética camponesa.

Segundo Wanderley (1996), a origem do conceito de camponês está relacionada à realidade da idade média europeia, mas a formação do campesinato brasileiro guarda grandes especificidades. No Brasil, o campesinato é criado no seio de uma sociedade capitalista e à margem de um latifúndio escravocrata. Em contraste com o forte enraizamento territorial que caracteriza o camponês europeu, a trajetória do nosso campesinato é marcada por uma forte mobilidade espacial. O predomínio de sistemas de posse da terra tem resultado numa condição de instabilidade, que faz da busca de novas terras uma importante alternativa de reprodução social. Assim, o seu modo de vida é considerado como um patrimônio - mais do que a terra - e é ele que tem sido, de fato, transmitido. Em função destas especificidades, Wanderley também usa, de forma mais intensa, o conceito de campesinidade.

Nesse contexto, não é possível pensar o assentamento de Canudos - fundado sobre uma comunidade centenária ${ }^{13}$, representada por sujeitos sociais que se identificam com a pesca artesanal e o plantio familiar - de forma dissociada, pois a atividade da pesca e da agricultura se fazem presentes concomitantemente. Para pensar a forma de apropriação dos territórios de terra e água em diferentes comunidades, inicialmente recorre-se a Diegues (2005). Para esse autor, há diferentes maneiras de as populações se apropriarem dos territórios. Para as sociedades, que ele denomina de "sociedades tradicionais", a água é um bem de uso essencial e, em geral, coletivo. No entanto, o uso da água tem dimensões conflituosas e políticas - a construção de sistemas de irrigação é um exemplo de atividade geradora de conflito. Em algumas situações, existem conflitos entre formas tradicionais de apropriação social dos espaços aquáticos, baseados no direito consuetudinário, e a apropriação mercadológica dos bens naturais. Para muitas comunidades de pescadores artesanais, o acesso à pesca é aberto

\footnotetext{
13 Usa-se o termo comunidades centenárias em substituição ao conceito de comunidade ou sociedade tradicional, pois, segundo essa concepção, o termo tradicional engessa a possibilidade de pensar e analisar as mudanças engendradas pelos sujeitos históricos; mas, ressalta-se que ambos os conceitos carregam uma ideia abstrata de temporalidade. Entretanto, o conceito de "centenária" tira a perspectiva de congelamento trazido pelo conceito "tradicional" e adiciona historicidade às comunidades camponesas. É neste sentido que se advoga que comunidades "centenárias", para um país pós-colonialista, é um conceito mais denso do que o conceito "tradicional", que remete ao exotismo da atemporalidade.
} 
somente aos membros da comunidade, que mantêm entre si relações de parentesco, pois a água, incluindo rios e lagos, faz parte de um território e de um modo de vida que serve de base a identidades específicas.

Nesse trabalho, o autor salienta que "pescadores artesanais" têm um modo de vida baseado principalmente na pesca, ainda que exerçam outras atividades econômicas complementares, como o extrativismo vegetal e a pequena agricultura. Conforme Diegues (2005), nestas mesmas comunidades há indivíduos mais ligados à terra, que vivem da junção das atividades agrícolas realizadas nas várzeas dos rios, do extrativismo e da pesca, respectivamente. Essas atividades simbióticas também foram encontradas em campo quando foi constatada a transversalidade das atividades da pesca e da lavoura no assentamento de Canudos, estabelecendo uma complementaridade entre o período da pesca e da atividade perene do plantio da mamona. Assim como muitos informantes associados à colônia de pescadores apresentaram um sentimento de pertencimento voltado para a pesca, o sentimento de pertencer à terra também foi sugestionado por outros informantes. Muitos assentados da comunidade de Canudos, que não estão ligados à pesca, afirmam que "o forte daqui é mamona". Canudos se apresenta, desta forma, como uma comunidade dividida e imersa numa realidade dual e conflituosa, em que a identidade do assentado e do morador ora se liga à agricultura e à ancestralidade, ora se liga à atividade da pesca e às lembranças do deslocamento sofrido por parte dos moradores.

No entanto, comunidades pesqueiras artesanais apresentam uma particularidade que a distingue do campesinato tradicional e que passa despercebida pelos técnicos responsáveis pelo gerenciamento das políticas públicas voltadas para a agricultura familiar e a pesca artesanal. Estas atividades são eminentemente simbióticas em comunidades tradicionais de beira-rio ou beira-mar, como observa Woortmann (1991):

Quando se fala de comunidades pesqueiras, imagina-se, muito frequentemente, atividades produtivas e agentes sociais relacionados apenas à pesca. Por outro lado, os estudos relativos a essas comunidades tendem a privilegiar o ponto de vista do homem, isto é, do pescador. No entanto, não é incomum que nessas comunidades haja também agricultura, além da pesca, como é o caso do grupo estudado por Peirano (1975) no Ceará e por Beck (1981) em Sta. Catarina, [...]. Em vários grupos, como o estudado por Maués (1977) e aqueles que são o foco deste trabalho, a agricultura é pensada como atividade feminina. Privilegiar o ponto de vista masculino seria negligenciar as atividades agrícolas que constituem o domínio das mulheres (p. 2).

Em Canudos, essa situação não é de todo distinta. Entretanto, o trabalho na caatinga ou nas roças de ilha ou beira de rio não são atividades exclusivas do domínio feminino. As atividades realizadas nas roças de caatinga e nas roças de lameiro são desenvolvidas tanto por mulheres quanto homens. De acordo com Woortmann (1991), nas comunidades pesqueiras, os homens estão mais próximos ao território de água; porém, em Canudos, mesmo os homens que possuem uma relação de pertencimento maior com a pesca realizam atividade de plantio, principalmente nas roças de ilha (lameiro), que se localizam em áreas próximas aos pesqueiros. Como a roça de mamona também tem importância significativa na renda destes grupos familiares, em momentos de acúmulo de trabalho, eles também participam da colheita desta oleaginosa. Portanto, com algumas exceções, pensar os assentados de Canudos enquanto identificados simplesmente como pescadores artesanais ou como lavradores ou agricultores familiares seria um erro. As atividades variam conforme o ciclo das enchentes ou vazantes, da quantidade de pescado e conforme o preço ofertado pela saca de mamona.

No trabalho de pesquisa realizado no Rio Grande do Norte, Woortmann (1991) salienta que existem atividades de ajuda recíproca entre 
homens e mulheres, ligadas à terra e à água. No caso da terra, os homens participam do preparo do solo das terras soltas. No caso da água, as mulheres são responsáveis pela limpeza e conservação do pescado. Havia uma complementaridade em que a ajuda de um viabilizava o trabalho do outro. Mas, segundo ela, os homens da comunidade do Rio Grande do Norte, se perguntados se trabalhavam ou não na roça, a resposta era que apenas ajudavam. Em Canudos isso não ocorre. Quando indagados sobre esta atividade, a maioria dos homens respondeu que trabalhavam no rio e na roça. Alguns salientam que têm mais prazer em estar no rio pescando ou nas roças de lameiro, enquanto outros afirmam ter prazer apenas na "labuta com a terra", preferindo o plantio na caatinga ou nas roças de ilha. Mas, como não negam suas atividades de plantio, tanto de caatinga quanto de ilha, sugere-se que a bipolaridade (terra $x$ água) em Canudos é mais diluída.

Assim, no assentamento de Canudos, o trabalho feminino não é reconhecidamente uma ajuda, mas um trabalho complementar ao trabalho masculino. Contudo, há ressalvas, pois existem homens que optaram por não trabalhar com o plantio e viver apenas da pesca. O único espaço de domínio da mulher é a casa/quintal. As atividades desenvolvidas dentro deste espaço são, geralmente, negligenciadas como trabalho. $\mathrm{O}$ fato de o trabalho feminino em Canudos não ser considerado uma ajuda, não significa que a atividade desempenhada pela mulher tenha a mesma importância hierárquica quando desempenhada pelo homem. Apesar da visibilidade do trabalho feminino em várias atividades, existe uma evidente hierarquia pautada em gênero. Segundo o imaginário dominante do grupo, os homens ainda capinam a roça melhor e mais rápido. Com relação às atividades comerciais, são os homens que decidem para quem e por quanto venderão a mamona colhida pelas suas mulheres e filhos.

A hierarquia também pode ser vista nessa bipolaridade entre os territórios de terra e água, quando a temática é a alimentação. A autora afirma que existe uma relação hierárquica entre o trabalho e o produto do mar ou da terra, pois, mesmo havendo uma complementaridade entre a alimentação originada desses dois territórios, o peixe era mais valorizado culturalmente como alimento, ou seja, ele era um alimento por excelência, correlatamente à construção social diferenciada dos gêneros. Em Canudos esta diferenciação sobre a valorização alimentar também ocorre. Mesmo a mulher e o homem trazendo da roça a mandioca, a batata, o feijão, ou mesmo havendo ovos para serem consumidos, o peixe é valorizado como um alimento mais forte. Conforme afirma Woortmann, se o mar é percebido como um lugar de trabalho do homem, a terra é seu lugar de lazer e descanso; é na terra que ele repousa, que festeja e que ingere bebidas alcoólicas. Em Canudos, mesmo que o homem trabalhe na roça por alguns dias, colaborando com a mulher, haverá dias que ele se recusará a trabalhar apenas para beber e jogar baralho, dominó, ou mesmo apenas "jogar conversa fora" nas vendas da comunidade.

Woortmann (1991) afirma que existe uma superioridade ideológica do homem, expressa na autorrepresentação do grupo do Rio Grande do Norte, de maneira contrastiva em face de outros grupos de agricultores. Mas, não obstante, há uma complementaridade entre os domínios masculinos e femininos, que foi se perdendo em função do advento do turismo na região. Com o turismo, as terras soltas desapareceram e a atividade da mulher com a agricultura e com o extrativismo foi altamente impactada. A mulher se tornou cativa, pois passou a depender de trabalhos de temporada nas casas de veraneio, enquanto o homem continuou em liberdade no mar. Esse processo de mudanças mudou o status feminino local. Antes da indústria turística e do cercamento das terras, a relação masculino/feminino era de complementaridade. Na atualidade, a relação da mulher é de completa dependência com relação ao mundo masculino. Este fato acarretou sérios problemas, como o aumento da violência doméstica, da prostituição das jovens, e também da gravidez precoce com filiação desconhecida.

Em Canudos, observa-se que a relação de complementaridade ainda é fundamental para 
a constituição social, cultural e econômica desta comunidade. Há não apenas uma complementaridade entre os territórios da terra e da água, como também entre os domínios masculinos e femininos. Entretanto, mesmo havendo uma complementaridade nas comunidades pesqueiras e agricultoras, existe uma identidade mais demarcada da mulher com a terra, que, por sua vez, impulsiona a manutenção do patrimônio familiar por meio desta atividade.

Estudos (GARCIA, 1983; WOORTMANN, 1991; WOOTMANN, 1997) apontam que as mulheres têm papel importante em relação aos arranjos internos do grupo doméstico e da família nuclear e extensa. O papel estrutural da mulher no interior das comunidades camponesas estabelece estratégias, às vezes invisíveis aos olhos dos técnicos governamentais, para a preservação do patrimônio familiar. Outra dinâmica que ressalta a importância do papel da mulher na preservação da reprodução do grupo social ou da preservação do patrimônio é a evidenciação da estratégia da pluriatividade através das atividades com a terra em conjunto com atividades não agrícolas ${ }^{14}$.

Ramalho (2001) é outro autor que retrata como o sentimento de pertencimento entre pescadores artesanais com o território de água são construídos. Para ele, é essencial entender o sentimento de pertença como maneira de posse (individual e comunal) das águas, pois é essa combinação, em relação à posse, que origina as formas de usos do território. Criar uma relação de pertencimento com o mar (no caso de Canudos, com o rio São Francisco) é criar e manter uma comunhão com esse recurso ecológico, traduzida na habilidade do pescador em descobrir os caminhos mais pro-

14 Admite-se que a agricultura familiar no Nordeste não sobrevive exclusivamente das atividades agrícolas, mas de um sistema de atividades geradoras de renda e que fazem parte das estratégias de reprodução. Trabalhos não agrícolas referem-se a situações sociais em que os indivíduos que compõem uma família com domicílio rural passam a se dedicar ao exercício de um conjunto variado de atividades econômicas e produtivas, não necessariamente ligadas à agricultura ou ao cultivo da terra, e cada vez menos executadas dentro da unidade de produção (SCHNEIDER, 2003, p. 101). Sobre esse assunto, ver Schneider (2003) e Schefler (2007). pícios para se tirar o que as águas têm de melhor a oferecer. De acordo com Ramalho (2001), existem diferenças quanto à noção de posse de um território por parte dos camponeses em relação aos pescadores artesanais, pois os pescadores lidam com um recurso de acesso livre e móvel (mar de dentro e mar de fora). ${ }^{15}$ Existem, por exemplo, locais de uso comum que são conhecidos e usados por todos os homens - como um bem comunal. Mesmo que o segredo sobre um novo pesqueiro e sobre melhores técnicas não possa ser guardado por muito tempo, tentar guardá-lo é importante para o mestre e/ou sua equipe, revelando seu talento. Na pesca, esses segredos só são revelados, sobretudo, a parentes, o que já caracteriza uma grande diferença entre a teoria do campesinato aplicada ao território da água, pois o saber do camponês não é um segredo, ele não é guardado, e sim repassado.

Em conformidade com Diegues (2005), o trabalho de Ramalho (2001) relata que os mestres são quem estruturam os acordos morais e as regras de uso das águas nas comunidades pesqueiras (usos comuns e/ou individualizados). Porém, é necessário ressaltar que o uso comum não significa falta de conflitos. Como no assentamento de Canudos, na comunidade estudada por Ramalho, na hora de sair para o pesqueiro, vale quem chegar primeiro. Quem tiver a primazia da chegada tem o direito de começar a soltar a rede primeiro, e só depois sair para que a outra equipe de pescadores (geralmente dois) possa fazer uso. Regras também existem para o uso de barcos ou redes e, assim como no campesinato, elas se baseiam em parentesco, amizade, cooperação, hierarquia e compadrio. Ou seja, existe uma ética pesqueira. Segundo Maldonado (1994), com a descoberta do segredo, o mar de dentro e o mar de fora deixam de ser espaços e passam a ser lugares, porque o espaço representa amplitudes sem demarcações claras. É a partir dessa territorialidade que o pescador mantém algum controle sobre determinados espaços, intercalando momentos individuais

15 Sobre esse assunto, ver Maldonado (1994). 
e coletivos de uso, fazendo-o lugar e, com isso, dotado do sentimento de pertença.

Nesta mesma perspectiva, a etnografia de Fraxe (2000), sobre a relação dos ribeirinhos e camponeses da várzea do Rio Solimões, traz uma análise ímpar da riqueza material e lúdica estabelecida por um grupo social com o seu território. O ribeirinho estudado por Fraxe, como os beraderos de Canudos, exercem simultaneamente múltiplas atividades, e nenhuma de modo exclusivo. Eles são sujeitos sociais (metaforicamente identificados como homens anfíbios e, sociologicamente, como camponeses) que vivem em dois ambientes - a terra e a água. Esse sujeito, segundo a autora, apresenta uma produção extremamente interligada, que explora os recursos renováveis através das atividades de agricultura e do extrativismo vegetal e animal, em que a pesca artesanal dos ribeirinhos do Rio Solimões (assim como ocorre em Canudos) é uma atividade primordial para a reprodução do seu modo de vida. A prática da agricultura ocorre nos ecossistemas de várzeas e terra firme - que, em Canudos, corresponderia à roça de lameiro e à roça de sequeiro. Estes camponeses retratados por Fraxe (2000) também são agentes de produção e de consumo, e o pai de família também é visto como o agente principal, que gera os recursos e as atividades do grupo. Assim como os moradores de Canudos, suas unidades familiares também determinam o equilíbrio entre a produção e o consumo, produzindo boa parte do alimento internamente, por meio da mão de obra familiar, e adquirindo poucas mercadorias (lamparina, sabão, café, sal, vestuário) por meio da troca ou por dinheiro, proveniente da venda de produtos excedentes (da pesca e da roça).

Como no assentamento de Canudos, a várzea do ribeirinho amazonense está ligada ao regime fluvial, e não à alternância de estações secas e chuvosas. O rio começa a subir em novembro, atinge o clímax de março a abril e cai em agosto, chegando ao mínimo em outubro. Com a retração das águas, as partes mais baixas da várzea, que geralmente ficam afastadas do rio, retêm a fauna aquática em lagos, de forma a tornar a caça e a pesca altamente produtivas. Segundo a autora, eles trabalham na terra de várzea parte do ano (de setembro a abril no solo enriquecido pelo limo) e os outros meses em terra firme, pois a várzea fica submersa. Nela se apresenta o cultivo de ciclo curto. A várzea mais alta é usada para agricultura, caça e extrativismo. $O$ cultivo de gêneros na várzea alta é de ciclos maiores.

Assim como em Canudos, os quintais do camponês anfíbio também têm grande importância na manutenção do grupo. Nos quintais, são plantadas árvores frutíferas, hortaliças, plantas ornamentais e medicinais e, novamente como em Canudos, os trabalhos realizados nesse lugar são, prioritariamente, executados por mulheres e crianças de ambos os sexos. Os sítios localizam-se geralmente em cotas mais altas da propriedade, e é nesse espaço que, durante as grandes enchentes, a unidade familiar tem a possibilidade de produzir alimentos para a sua subsistência. Conforme Fraxe (2000), este campesinato trabalha a terra, quase que exclusivamente com mão de obra familiar. Porém, vendem a sua força de trabalho quando a subsistência da unidade familiar está ameaçada por uma colheita não satisfatória, em razão de enchentes, pragas ou para apropriarem-se de algum excedente, sempre visando à manutenção da família. Durante quatro ou cinco meses, grande parte da planície terrestre fica encoberta e, assim, esse campesinato amazonense é compelido ao assalariamento, ou na cidade como subproletário, ou no campo, por meio de empreitada na pesca ou em outras atividades. Da mesma forma que no assentamento de Canudos, os homens anfíbios praticam a pluriatividade e as mulheres vivem o seu cotidiano como mães, domésticas, extratoras e agricultoras. Entretanto, ao contrário de Canudos e dos pescadores agricultores estudados por Woortmann (1991), as mulheres ribeirinhas do rio Solimões são pescadoras. Em Canudos, porém, as mulheres só pescam com seus filhos menores, por diversão, nos barrancos, e apenas nos fins de semana. Suas pescarias são economicamente desconsideradas, pois é avaliada como um lazer, em que apenas peixes de pequeno porte são fisgados. Conforme observado em muitas etnografias sobre campesi- 
natos tradicionais, apesar da "estrutura estruturada" tornar implícito que, na divisão sexual do trabalho, as mulheres não devem executar tarefas pesadas, as "estruturas estruturantes" exigem delas um sobretrabalho. Nas etnografias já citadas, verificam-se muitas atividades que, na falta de homens, são executadas por mulheres. As crianças também participam do processo de trabalho, e os idosos realizam tarefas leves, ligadas, geralmente, às atividades de subsistência. Algo relevante a ser considerado é que nem Fraxe nem Woortmann ressaltam a existência da renda mensal da aposentadoria desses idosos para a manutenção da unidade familiar. Como estas etnografias foram realizadas em períodos anteriores à implantação maciça destas políticas redistributivas, este deve ser o motivo de as autoras não trazerem estes dados para os seus respectivos trabalhos.

Como pode ser observado, no assentamento de Canudos existe uma relação entre os sujeitos sociais e os ecossistemas, que permite que eles os ocupem, controlem e se identifiquem com esses espaços, transformando cada um deles em lugares significativos. Mas a forma com que esses grupos sentem seus lugares, como organizam suas estratégias e desempenham as suas atividades possui particularidades. Moradores que desenvolveram um sentimento de pertença maior com a pesca artesanal do que com a terra terão uma percepção distinta do território ou das necessidades intervencionistas, do que os moradores que se identificam com o plantio. Da mesma forma, moradores que nasceram na comunidade (estabelecidos ou "de dentro" $)^{16}$, independente da proximidade das moradias e das atividades que realizam, parecem não conseguir romper com o distanciamento entre eles e as famílias posteriores (outsiders ou "de fora"); um distanciamento estabelecido

\footnotetext{
16 As pessoas são categorizadas pela categoria êmica como "de dentro" ou "de fora", conforme a sua unilinearidade (o homem identifica a categoria na qual seus filhos e filhas serão integrados na comunidade), e essa questão é de suma importância. No entanto, em Canudos, os moradores têm dificuldade em verbalizar ou se perceber como um "de fora". Sobre esse assunto ver Woortmann (1990), Cardel (1987, 1992, 2003) e Godói (1999).
}

por serem de lugares distintos, pois a maioria das famílias de Canudos sempre teve modus vivendi beradero. No entanto, questões como essas não foram levadas em conta para a criação do espaço artificial do assentamento, pois, apesar do assentamento de Canudos aparentar ser uma comunidade de pescadores artesanais e agricultores familiares beraderos, típica do Médio São Francisco, sua história de constantes intervenções mudou sua organização social e ela se encontra extremamente fragmentada.

Entender os significados de um determinado território - assentamento - pressupõe uma reflexão anterior sobre a ocupação de terras no Brasil, suas transformações e conflitos. Conflitos não necessariamente atuais, mas que refletem uma história relacionada com a ocupação do território brasileiro. Conflitos que, em muitos casos, parecem ser um reflexo da ação ou da omissão do Estado brasileiro. O caráter expropriador da questão fundiária no Brasil tem deixado inúmeros camponeses sem acesso à terra. Estes, quando não migram para as cidades de forma circulatória, estabelecem relações de parcerias, agregação, ou buscam, por meio da mobilização, ocupar terras não produtivas, pressionando as políticas de assentamento.

Embora o assentamento de Canudos apresente intervenções desastrosas por parte dos mediadores e do poder público em várias esferas frente à pauperização da comunidade, este grupo social não deixou de tecer aspectos essenciais de seu modo de vida, utilizando várias estratégias de sobrevivência, como a renda com a pesca, com a mamona, o plantio em área de lameiro e vazante, com a migração sazonal e circulatória, e, fundamentalmente, com as rendas dos benefícios das políticas públicas, como os da previdência social e os da transferência de renda (principalmente da Bolsa Família e as aposentadorias para trabalhadores rurais). O trabalho de campo ressaltou características peculiares de um grupo social que, apesar de fragmentado, compartilha entre os seus grupos domésticos um certo imaginário camponês, em que a terra e a água se complementam. E, assim como o grupo de camponeses estudados 
por Fraxe (2000), as características mais peculiares deste campesinato são a dependência em relação aos ciclos naturais de estiagem e de chuva; o intenso conhecimento destes ciclos que se refletem nas estratégias de manejo; a noção de território; o uso de tecnologia simples, tanto no plantio quanto na pesca; a pequena produção para o consumo e a venda; a opção pela policultura; a utilização de mão de obra predominantemente familiar; a hierarquia paterna; e a divisão de trabalho pautada nas relações de gênero e geração. Em resumo, o grupo camponês do assentamento de Canudos é constituído por famílias lavradoras e pescadoras que primam pelo trabalho familiar e que possuem uma relação complexa com o território que ocupam. Entretanto, por todas as particularidades da história recente desta comunidade, Canudos não se constitui como um campesinato histórico típico, em função do seu déficit de sociabilidade. A identidade do grupo apresenta-se fragmentada entre as atividades realizadas nos territórios de terra e de água, e as relações intergrupais não estão pautadas nas relações simétricas e familísticas do parentesco real e espiritual, ao contrário da realidade de grande parte do campesinato sertanejo brasileiro. Assim, as práticas de ajuda mútua, também conhecidas como mutirão, não são típicas desta comunidade, artificialmente recriada pelo Incra.

Apesar de Canudos ter sido criado na década de 1990, os lotes ou os terrenos das unidades familiares assentadas ainda não foram demarcados pelo Incra. Assim, o local e a quantidade de terra trabalhada pela unidade familiar estão vinculados a uma maior ou menor precedência das famílias na localidade, como também à quantidade de mão de obra de que cada grupo doméstico dispõe. Esta realidade imposta é o nó górdio desta comunidade e a fonte dos seus conflitos estruturais e cotidianos. Destarte, sem que o Estado tenha terminado de realizar o seu papel como implementador de um espaço organizativo, os assentados criaram formas próprias de ocupação. E, dentro desta lógica, as famílias camponesas de Canudos plantam particularmente em áreas individuais e em áreas consideradas comunais. Seguindo esta lógica, as plantações em terrenos de ilha ou beira de rio (áreas proibidas pelo Ibama) foram inicialmente sendo demarcadas pela precedência, e posteriormente pela capacidade de adquiri-las mediante pagamento. Entretanto, se a lógica da renda fundiária se impôs no território de terra, no território de água, as regras se efetivaram de forma mais rígida e clara. Neste lócus de trabalho, os espaços de pesca não são individuais, e a ordem dos barcos que se aproximam primeiramente dos pesqueiros é rigorosamente respeitada. Existe, inclusive, um acordo tácito entre os pescadores da comunidade, que os impede de pescar em frente às roças de ilha que não as suas. Assim, de forma tortuosa e conflitual, algumas regras foram sendo estabelecidas entre os grupos domésticos do assentamento, para que um mínimo de sociabilidade fosse criado. Curiosamente, o espaço mais regulamentado não é o que foi desapropriado para o assentamento, mas as áreas públicas que circundam a comunidade, como as áreas de beira de rio e as ilhas fluviais.

\section{Conclusão}

Com relação às estratégias de sobrevivência dos grupos domésticos, em Canudos há uma somatória entre a renda da terra, a renda da água e os benefícios da previdência social e de transferência de renda que propiciam certo equilíbrio para o grupo. Isso significa dizer que a necessidade econômica e a busca pelo equilíbrio da unidade doméstica podem, portanto, impor procedimentos, violação de costumes e modificações constantes. Há, por exemplo, violações de hábitos basilares da campesinidade, como a baixa reciprocidade, e circulam entre os grupos mais "recursos informacionais" (LOERA, 2006) e fofocas do que recursos materiais. Ao contrário de outras comunidades camponesas, inclusive comunidades circunvizinhas ${ }^{17}$, em Canudos, a doação de pes-

\footnotetext{
17 Ver os estudos de Cardel $(1992,2003)$ e de Viana (2009) sobre outras comunidades camponesas do município de Barra (BA).
} 
cado, de carne de caça e de animais domésticos e o empréstimo de grãos entre famílias são hábitos inexistentes.

Apesar de alguns moradores terem se declarado apenas como lavradores e outros como pescadores, não existe no assentamento uma atividade exclusiva: as atividades de plantio e pesca são simultâneas e complementares. No que concerne aos grupos sociais salientados, observa-se que a autoidentificação tem relação com o sentimento de pertencimento a um ou a outro território, e com a política pública à qual está vinculado. A identidade de lavrador, que, de acordo com a descrição sobre o grupo, é alicerçada no imaginário da organização camponesa, é positivada se o individuo for aposentado como trabalhador rural ou recolher para a previdência com este intuito. Da mesma forma, o assentado que se autoidentifica como pescador, além de preferir esta atividade, geralmente é associado à colônia de pescadores e recebe o defeso ${ }^{18}$ ou é aposentado como pescador artesanal. No entanto, a maioria se autoidentificou como portador das duas identidades sociais, mesmo não sendo legalmente ligados à colônia de pescadores ou à associação de produtores. Em resumo, na comunidade pesquisada, mesmo após o benefício da política pública de assentamento, a identidade de lavrador ou de trabalhador rural não se tornou homogeneizante, visto que a identidade social do grupo é composta por elementos ligados à terra e à água. Conforme os dados coletados sobre a realidade social de Canudos, os assentados lidam muito bem com a duplicidade identitária por eles estabelecida.

Por fim, é neste contexto de contradições e de rearticulações sociais e históricas que, no assentamento de Canudos, as práticas da agricultura

\footnotetext{
18 "É o período em que as atividades de caça, coleta e pesca esportivas e comerciais ficam vetadas ou controladas em diversos locais do território nacional. Este período é estabelecido pelo Ibama de acordo com o tempo em que os crustáceos e os peixes se reproduzem na natureza. Visa a preservação das espécies e a fruição sustentável dos recursos naturais. Os pescadores artesanais recebem do governo proventos em dinheiro durante a época em que não podem obter renda da pesca por impedimento legal" (Disponível em: http://www.ibama.gov.br).
}

familiar, da pesca artesanal e do extrativismo se articulam de forma entrelaçada ao sistema pluriativo. Desta forma, a adesão à pluriatividade colabora para que o grupo camponês em voga se situe em um emaranhado formado por uma multiplicidade de identidades sociais, em que a identidade única, na práxis, não existe. De acordo com Cardel (2010), os grupos sociais produzem teorias sociais sobre si mesmos, que, por questões micropolíticas, são expressões de lutas internas e de relações assimétricas. Para afiançar esta afirmação, é de suma importância estar atento às lutas objetivas e intersubjetivas travadas em situações micropolíticas cotidianas, pois é por meio delas que os sujeitos se autorrealizam ${ }^{19}$, como é o caso dos assentados da comunidade de Canudos. Analisar as contradições desta realidade foi a finalidade desta investigação. Entretanto, salientamos que em nenhum momento é desejado encerrar todas as questões levantadas por este trabalho. Este artigo traz elementos e dados que são considerados importantes, a partir do estudo de caso, e significativos para que as políticas públicas voltadas para a implementação de assentamentos rurais e de incentivos à agricultura familiar sejam reavaliadas, levando-se em consideração as reais necessidades do campesinato brasileiro, que apresenta multiplicidade de singularidades e estratégias incompreendidas pelas atuais políticas estatais.

\section{Referências bibliográficas}

CANDIDO, A. Os Parceiros do Rio Bonito: estudo sobre o caipira paulista e a transformação dos seus meios de vida. São Paulo: Ed. 34, 2001. (Coleção Espírito Crítico)

CARDEL, L. Ma. P. S. Forte e Fraco, Dentro e Fora: Categorias Culturais e Estrutura de Comunidade. Monografia de conclusão do curso em Antropologia Social. UNB, 1987.

\footnotetext{
19 Segundo Sabourin (1999), a ineficiência de algumas políticas públicas em comunidades rurais muitas vezes está ligada à ignorância por parte do Estado e dos mediadores sobre a lógica de reciprocidade, inerente a muitos desses grupos. Em maior ou menor grau, estas políticas públicas apresentam apenas propostas de desenvolvimento mercantil (cooperativismo, associativismo), criando, assim, outros problemas.
} 
. Os Olhos que Olham a Água: Parentes e Herdeiros no "Mundo Camponês". Dissertação (Mestrado) - Brasília: UNB. Programa de Pós-graduação em Antropologia da Universidade de Brasília, 1992.

. Migração, Liminaridade e Memória: um estudo sobre o choque entre imaginários e (re)construções de identidades. Tese (Doutorado) - São Paulo: USP Programa de Pós-graduação em Antropologia da Universidade de São Paulo, 2003.

Algumas considerações sobre Identidade, Sociabilidade e Etnogênese e seus atuais contornos políticos. Revista: O Olho da História, n. 14, Salvador/BA, jun. 2010.

CARVALHO, H. M. A Interação Social e as Possibilidades de Coesão e de Identidade Sociais no Cotidiano da Vida Social dos Trabalhadores Rurais nas Áreas Oficiais de Reforma Agrária no Brasil, 1999. Disponível em: <www.nead. gov.br/portal/nead/arquivos/view/textos-digitais/ Artigo/arquivo15.pdf > . Acesso em: 4 mai. 2009.

DAOU, A. M. Políticas de Estado e Organização Social Camponesa: a barragem de sobradinho. Dissertação (Mestrado) - Rio de Janeiro: Museu Nacional. UFRJ/ PPGAS, 1988.

DIEGUES, A. C. Aspectos Sócio-Culturais e Políticos do Uso da Água. Plano Nacional de Recursos Hídricos MMA. Núcleo de Apoio à Pesquisa sobre Populações e Áreas Úmidas Brasileiras/NUPAUB - USP, 2005.

DUFUMIER, M. Projeto de Desenvolvimento Agrícola: manual para especialistas. Salvador: EDUFBA, 2007.

ELIAS, N.; SCOTSON, J. Os Estabelecidos e os Outsiders. Sociologia das relações de poder a partir de uma pequena comunidade. Rio de Janeiro: Jorge Zahar, 2000.

ESTRELA, E. S. Três felicidades e um desengano: a experiência dos beraderos de Sobradinho em Serra do Ramalho - BA. Tese (Doutorado) - São Paulo: PUC. PPGH, 2004.

. Um Caso de deslocamento compulsório: o Projeto Especial de Colonização Serra do Ramalho - Bahia. Trabalhoapresentado no VIICongresso Latinoamericano de Sociologia Rural, Quito, Equador. 2006.

FRAXE, T.J. Homens Anfíbios. Etnografia de um Campesinato das Águas. São Paulo: Annablume; Fortaleza: Secretaria da Cultura e Desporto do Governos do Estado do Ceará, 2000.

GARCIA JR, A. Terra de Trabalho. Trabalho familiar de pequenos produtores. Rio de Janeiro: Paz e Terra, 1983.

GODOI, E. P. O Trabalho da Memória - cotidiano e história no sertão do Piauí. Campinas: Editora da UNICAMP, 1999.
HEREDIA, B. M. A. A morada da Vida. Rio de Janeiro: Paz e Terra, 1979.

LOERA, N. R. A Espiral das Ocupações de Terra. CERES, 2006.

MALDONADO, S. C. Mestrese Mares: Espaço e Indivisão na Pesca Marítima. 2. ed. São Paulo: Annablume, 1994.

MARTINS, J. de S. O Sujeito Oculto: ordem e transgressão na reforma agrária. Porto Alegre: Editora da UFRGS, 2003.

MARTINS-COSTA, A. L. B. Uma Retirada Insólita: A Representação Camponesa sobre a Formação do Lago de Sobradinho. Dissertação (Mestrado) - Rio de Janeiro: Museu Nacional. UFRJ/PPGAS, 1989.

MOURA, M. M. Camponeses. São Paulo: Ática, 1988. (Série Princípios)

QUEIROZ, M. I. P. de. O Campesinato Brasileiro: ensaios sobre civilização e grupos rústicos no Brasil. Petrópolis: Vozes, 1973.

. O messianismo no Brasil e no mundo. 2. ed. São Paulo: Alfa-Ômega, 1976.

RAMALHO, C. O Mundo Das Águas e Seus Laços de Pertencimento. Revista: Raízes, v. 23, n. 01 e 02, jan./dez. 2001.

REBOUÇA, L. M. O Planejado e o Vivido. Os projetos de reassentamento da Cesp no Pontal de Paranapanema. Dissertação (Mestrado) - Programa de Pós-graduação em antropologia Social. Universidade de são Paulo. 1997.

SABOURIN, E. Práticas de reciprocidade e economia de dádiva em comunidades rurais do Nordeste Brasileiro. Revista Raízes, Campina Grande, Ano XVIII, n. 20, nov. 1999, p. 41-49.

SCHEFLER, M. de L. N. Caderno de orientações metodológicas para Formadores: metodologia análisediagnóstico de sistemas de atividades, sob o enfoque de gênero e geração. Salvador: REDOR, 2007.

SCHNEIDER, S. Teoria social, agricultura familiar e pluriatividade. Revista Brasileira de Ciências Sociais, v. 18, n. 51, fev. 2003.

SIGAUD, L. As condições de possibilidade das ocupações de terra. Revista: Tempo Social, USP, v. 17, n. 1. 2005.

SILVA, M. A. de M. A luta pela terra: experiência e memória. São Paulo: UNESP, 2004.

VIANA, G. B. Entre a terra e o rio: um estudo sobre o processo de vizibilização do trabalho feminino no 
campo. Monografia de conclusão do curso de Ciências Sociais. Salvador: UFBA, 2009.

WANDERLEY, M. de N. Raízes Históricas do Campesinato Brasileiro. Encontro Anual da ANPOCS. GT: Processos Sociais Agrários. MG: Caxambu. Outubro, 1996.

WEBER, M. Capitalismo e Sociedade Rural na Alemanha. In: Os Pensadores. São Paulo: Abril Cultural, 1980.

WOORTMANN, E. F. Da Complementaridade à Dependência: a mulher e o ambiente em comunidades "pesqueira" do Nordeste. Série Antropológica 111. Brasília, 1991.

WOORTMANN, K. "Com parente não se neguceia": o campesinato como ordem moral. In: Anuário antropológico 87. Brasília: Editora Universidade de Brasília, 1990.

; WOORTMANN, E. F. O trabalho da terra: a lógica e a simbólica da lavoura camponesa. Brasília: Editora Universidade de Brasília, 1997. 


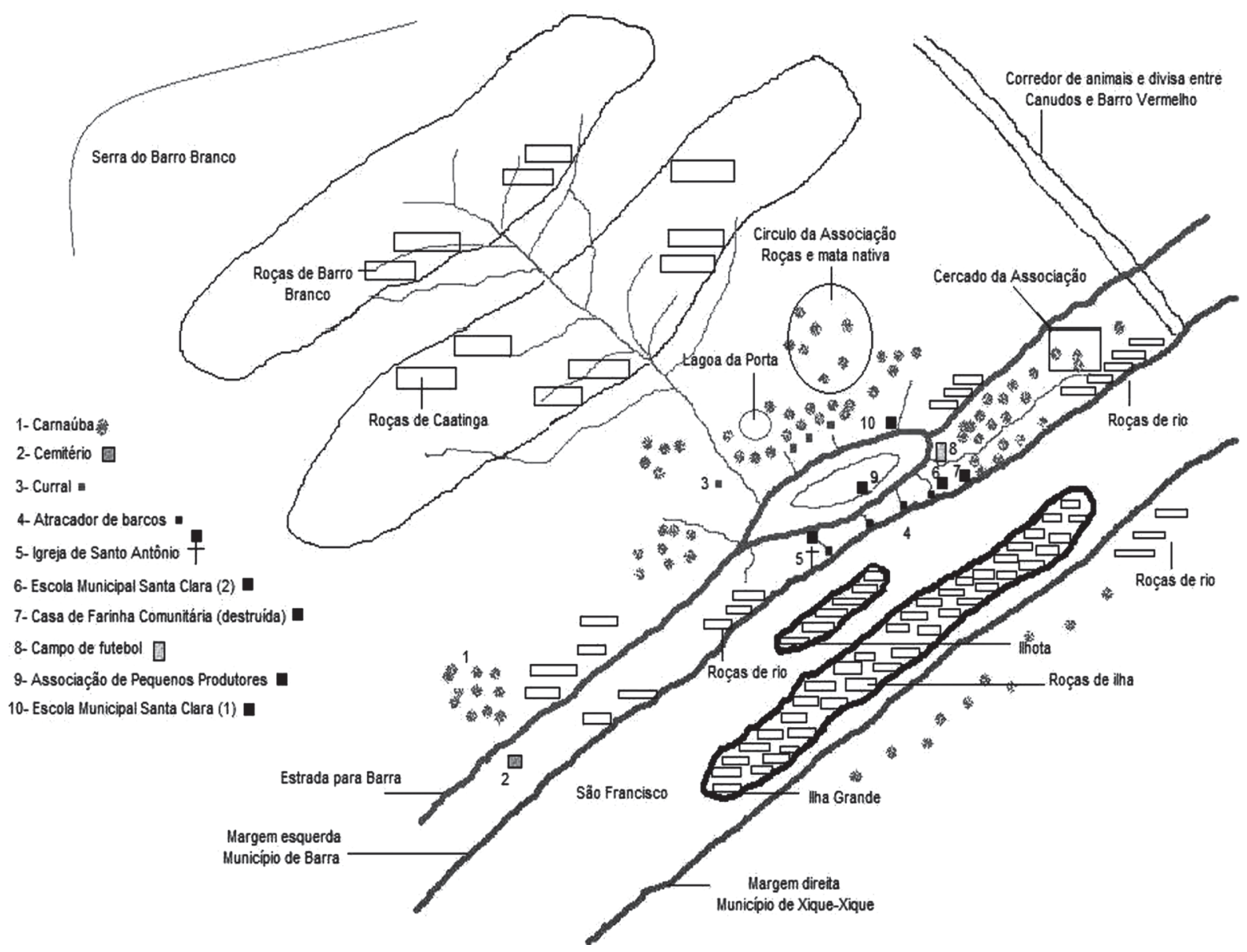

Fonte: Croqui realizado em campo, em setembro de 2010, por Rejane Alves de Oliveira. 